\title{
Exploring the Relationship between Body Mass Index and Anxiety Status among Ahlia University Students
}

\author{
Sayed A. Tantawy ${ }^{1,2 *}$, Nada Ikram Karamat ${ }^{1}$, Rana Sulaiman Al Gannas ${ }^{1}$, Sara Abdulrahman Khadem ${ }^{1}$, Dalia M. Kamel ${ }^{1,3}$ \\ ${ }^{1}$ Department of Physiotherapy, College of Medical and Health Sciences, Ahlia University, Manama, Kingdom of Bahrain; \\ ${ }^{2}$ Department of Physiotherapy, Centre of Radiation, Oncology and Nuclear Medicine, Cairo University, Giza, Egypt; ${ }^{3}$ Department \\ of Physical Therapy for Women's Health, Faculty of Physical Therapy, Cairo University, Egypt
}

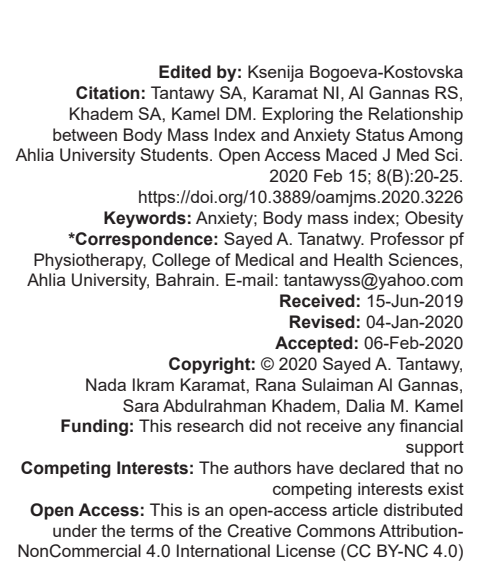

Abstract

BACKGROUND: Mood disorders such as generalized anxiety disorder (GAD), obsessive-compulsive disorders and other mental disorders could be due to obesity which is a prevalent condition among majority of population nowadays, whereas changes in anxiety level of individuals are also thought to have an influence on body mass index (BMI).

AIM: The objective of the study was to investigate the relationship between BMI and anxiety status among Ahlia University students.

METHODS: A total of 80 male and female students from different colleges of Ahlia University were included in our study. Their ages ranged between 18 and 25 years old with different BMI. The students were asked to fill a (GAD 7 scale) questionnaire related to anxiety level; their BMI was calculated.

RESULTS: There was a significant relationship between BMI and anxiety status (negative correlation) $(p<0.019)$. CONCLUSIONS: We concluded that BMI is inversely proportional to anxiety level, the reduction in BMI level is linked with elevated anxiety level and vice versa.

\section{Introduction}

Anxiety can be defined as a mood state in which feelings of fear predominate, and the fear itself is out of proportion to any threat. It can be associated with physical symptoms, which may include fast pulse rate, palpitations and sweating, shaking, pins, and needles [1].

Anxiety results in altered behavioral responses, patient's outcomes, and physiological functioning by triggering changes in the immune system and neuroendocrine functioning, which interact with health status and health behavior [2].

One of the major causes of mortality and morbidity in the United States is considered to be depression and anxiety which eventually leads to impaired social function and quality of life-related to health; these psychological conditions result in social impairment affecting an individual's desire of going out and meeting people [3].

Body weight adjusted for height is often used instead of the measurement of adipose tissue mass to evaluate individuals or populations for obesity. Such a measure that is widely used nowadays is Quetelet's index, known as body mass index (BMI), which is body weight in kilograms divided by height in meter square $\left(\mathrm{kg} / \mathrm{m}^{2}\right)$. Different studies show that BMI is a convenient measure of adiposity, given that body weight and height are simple, inexpensive, safe, and practical measurements to obtain [4], [5].

BMI correlates reasonably well with laboratorybased measures of adiposity for population studies and is extremely practical in most clinical settings [6].

Obesity involves abnormal accumulation of body fat, which causes systemic consequences leading to increased risk of several diseases such as diabetes. The World Health Organization consultation defined obesity as a chronic disease that is so common in both developed and developing countries that it is replacing the more traditional public health concerns, such as undernutrition and infectious diseases [7], [8].

In a study conducted in Bahrain about the prevalence of obesity in Bahrain showed that the number of overweight and obese individuals including children and adults has increased to significantly high levels during the past two decades, the reason for that 
was thought to be mostly due to the sedentary lifestyle, the lack of physical activity and possibly the unhealthy diet [9].

Around the world, obesity has been associated with several causes of mortality. Evidence from a recent review of 97 articles (including 37 in the United States) showed that obesity (BMI $\geq 30.0$ ) is associated with higher all-cause mortality risk [10], [11].

Obesity is considered a chronic disease in the same way as hypertension (HTN) and atherosclerosis. The etiology of obesity is an imbalance between the energy gained from food and the energy produced by the body as the energy gained far exceeds the energy produced by the body and in consequence, the energy remained unused is stored in the body as fat cells leading to increased body weight [12].

In 2007-2008, the prevalence of obesity was $32.2 \%$ among adult men and $35.5 \%$ among adult women while in 2013-2014 was $35.0 \%$ among men and $40.4 \%$ among women.

The prevalence of obesity (BMI $\geq 30$ ), among US adults, increased from approximately $23 \%$ in 1990 to $31 \%$ in 2000 [13], [14].

Previous research suggests that obesity might be significantly related to mood or anxiety disorders [15].

Obesity has been rapid spread among children and adults during the past two decades. Obesity can cause a variety of physical illnesses such as HTN, diabetes mellitus, and coronary heart disease but also there are links of obesity to mental disorders which may lead to depression and other psychological disorders. However, existing information on the relationship between obesity and depression is inconsistent. Some studies show that obese people are at higher risk to get depression, but other studies reported the opposite [16].

There is a conflicting evidence regarding the relationship between $\mathrm{BMI}$ and anxiety which classification of BMI has a greater risk of developing anxiety symptoms; our study aimed to investigate the relationship between BMI and anxiety, which helps to identify a modifiable risk factor for psychological disorders.

\section{Methods}

\section{Participants}

A total of 80 male and female students participated in this study. These subjects were recruited from different collages of Ahlia University. The study included healthy participants aged above 18 years who agreed to sign the consent form. Exclusion criteria include pregnant women, student's undergone surgery recently, and students taking medications for psychological disorders or pathological condition that affects their anxiety status. This study is crosssectional non-experimental research study designed to investigate the relationship between $\mathrm{BMI}$ and anxiety status among students of Ahlia University. Before any commencement of the study trial (baseline measurements and operation), written consent was obtained from all the participants. All data obtained and assessed during the period of study trial was kept highly confidential. Participants were free to withdraw from the research study anytime they wanted.

\section{Instruments}

Generalized anxiety disorders (GAD)-7 scale: It is a reliable scale used to measure the level of GAD

- Weight scale: To measure the weight of the participants, we used Nevica weight scale Height scale: To measure the height, we used Detecto stadiometer.

\section{Procedure}

Participants (both male and female) were gathered from Ahlia University, and they were explained about the purpose and procedure, and they were handed a written consent. Following the completion of the consent, the questionnaires were distributed among the volunteers; examiners were there to help them if they had any questions or doubts. Once the participant finished completed the questionnaires, their height and weight measurements were taken. Later, the BMI and anxiety scores were calculated by the examiners, and statistical analysis was performed to obtain the results.

\section{Questionnaire}

It is scale frequently used to measure the level of GAD. The scale consisted up of seven questions asked from the participants, and later on, the scores were given based on the answer. The values of GAD-7 scale ranged from 0 to 21 . The classification was as follows: 0-4: Minimal anxiety, 5-9: Mild anxiety, 10-14: Moderate anxiety, and 15-21: Severe anxiety were classified. The assessment is made by the total score of all the seven items. GAD-7 scores range from 0 to 21 , with scores of $5,{ }_{-} 10$, and $\_15$ representing mild, moderate, and severe anxiety symptom levels, respectively [17].

The GAD-7 scale which is used to monitor the level of GAD and accessing its level of severity in research as well as clinical practice is considered to be a valid. A study concluded that GAD-7 scale is a reliable 
tool and shows construct, factorial, and procedural validity. Its optimized sensitivity was $89 \%$ and specificity was $82 \%$ [18].

GAD: One of the chronic and prevailing conditions among adults is considered to be GAD, although it is still poorly understood. Excessive worrying about a situation and anxiety are common symptoms of GAD; however, the clinicians not necessarily recognize them as symptoms of psychological disorder. GAD usually starts from young adolescents, and its risk is increased with age, it is less associated with females than males [19].

If the period of excessive worrying persists 6 months or more, it is characterized as GAD and is not limited to particular circumstances. The most crucial symptoms of GAD include fatigue, restlessness, irritability, disturbed sleep, difficulty concentrating, and muscle tension; if three of them show up, it is characterized as GAD [20].

Anxiety disorders mainly show its onset before age of years, and the onset pattern of GAD is not the same as it is for anxiety disorders, rates for GAD are highest in middle-aged people and less prevalent during adolescence and young age [21].

\section{Weight}

Subjects were intended to stand over the center of the scale platform facing the examiner, look straight and the hand at the side until the examiner recorded the readings.

\section{Height}

\section{Position of the subject}

Height of the subjects was measured using stadiometer, subjects were instructed kindly to remove hislher shoes, stand with their feet flat on the center of the base plate, feet together, and heels against the rod. The subjects back were straight as possible, their arms hanging loosely by their sides and facing forward. Then, we moved the subjects head so that the Frankfort Plane is in a horizontal position (i.e., parallel to the floor). Then, we instructed the subject to keep their eyes focused on a point straight ahead and to breathe in deeply, and then stadiometer headpiece was lowered firmly on top of the head. Then, we asked the subject to step forward, after that, we looked at the bottom edge of the head plate cuff and record the reading of the subject's height.

\section{BMI}

The weight and height were used to calculate the BMI of each subject which is defined as the individual's body mass.

\section{Statistical analysis}

All of the data obtained were tabulated and inserted in the SPSS program "Statistical Package for the Social Sciences" (v.20; Lead Tech; Chicago) to perform the statistical analysis. Descriptive analysis was used to calculate the mean, standard deviation, and percentage. In addition, Pearson correlation test was used to investigate the relation between BMI and anxiety status. $p<0.05$ (level of significance) indicates a significant difference while $p>0.05$ indicates no significant difference.

\section{Results}

A total of 80 students from different colleges at Ahlia University included in this study. Their ages ranged between 18 and 25 years old. Out of these 80 students, there were 31 males and 49 females.

The total number of subjects and their respective percentages was classified, according to their BMI as underweight, normal, overweight, and obese. The maximum number of subjects (i.e., $45 \%$ ) had normal BMI, 19 out of 80 subjects (i.e., 23.75\%) were classified as obese. Over obese subjects were only five and made up the least percentage (i.e., 6.25\%), as shown in Table 1.

Table 1: The percentages of different classifications of BMI among all subjects

\begin{tabular}{|c|c|c|c|c|c|c|}
\hline \multirow[t]{2}{*}{ Variable } & \multicolumn{2}{|c|}{ BMI classifications } & \multirow[t]{2}{*}{ Overweight } & \multicolumn{3}{|l|}{ Obese } \\
\hline & Underweight & Normal & & Class 1 & Class2 & Class3 \\
\hline No of subjects & 6 & 36 & 19 & 8 & 6 & 5 \\
\hline Percentages $\%$ & 7.5 & 45 & 23.75 & 10 & 7.5 & 6.25 \\
\hline
\end{tabular}

Table 2 shows the number of students having various anxiety levels ranging from minimal anxiety to severe anxiety. The majority of students among male and the female were with mild anxiety, i.e., 11 males and 17 females. Very few students among males and females were found to have severe anxiety levels.

Table 2: Scores of anxiety level in both male and female subjects

\begin{tabular}{lll}
\hline Anxiety level & No. of males & No. of females \\
\hline Minimal anxiety & 6 & 8 \\
Mild anxiety & 14 & 20 \\
Moderate anxiety & 11 & 17 \\
Severe anxiety & 1 & 3 \\
\hline
\end{tabular}

The mean value of the BMl was $26.03 \pm$ 7.47. The minimum value of BMI was 16.4 , while the maximum was 49.31, as shown in Table 3.

Table 3: The mean, standard deviation, minimum and maximum values of BMI and anxiety level

\begin{tabular}{lllll}
\hline Variables & $\mathrm{n}$ & Minimum & Maximum & Mean \pm Standard deviation \\
\hline BMl & 80 & 16.4 & 49.31 & $26.03 \pm 7.47$ \\
Anxiety level & 80 & 0 & 16 & $8.51 \pm 3.72$ \\
\hline BMI: Body mass index.
\end{tabular}

The mean value of the anxiety level was 8.51 \pm 3.72 . The minimum value of the anxiety level was 0 , while the maximum was 16, as shown in Table 4. 
Table 4: The mean, standard deviation, minimum and maximum values of anxiety level

\begin{tabular}{lllll}
\hline Variable & $\mathrm{n}$ & Minimum & Maximum & Mean \pm Standard deviation \\
\hline Anxiety level & 80 & 0 & 16 & $8.51 \pm 3.72$
\end{tabular}

The current study showed a negative linear correlation $(r=-0.26)$ between the BMI and anxiety levels. Moreover, $\mathrm{p}=0.019$ indicates a significant relationship between $\mathrm{BMI}$ and anxiety status, as shown in (Table 3).

In this study, it was observed that six subjects were underweight (four subjects had moderate and two subjects had mild anxiety level). There were 36 subjects with normal BMI (six had minimal anxiety, 14 moderate, one severe, and 15 subject with mild anxiety level). For overweight students, the anxiety level was as follows, 3 - severe, 10 - mild, and 6 - moderate anxiety. Nineteen students were classified as obese (seven students with mild, eight with minimal, and four with moderate anxiety levels).

\section{Discussion}

A total of 80 males and females participated in this study. Their ages were between 18 and 25 years old $(20.3 \pm 2.2)$ with different BMI. These subjects were recruited from different colleges of Ahlia University.

Our study found a negative linear correlation $(r=-0.26)$ between BMI and anxiety status. $p=0.019$ indicates a significant relationship between BMI and anxiety level. The maximum number of subjects (45\%) had normal BMI, 19 out of 80 subjects $(23.75 \%)$ were classified as obese. Class III obesity subjects were only five and made up the least percentage (6.25\%). The majority of students among male and the female were with mild anxiety (11 males and 17 females). Very few students among males and females were found to have severe anxiety level.

McCaulay et al. (1988); Crisp and McGuiness (1976); and Ross (1994) [22], [23], [24] support our study. This negative correlation may be due to the following reasons:

McCaulay et al. [22] suggested that men judge a smaller body frame to be less preferable than a larger, more muscular one. In addition, lower body weight appears to be associated with a poorer body image than does heavier body weight among men. As some men consider a smaller body undesirable, a view that may be reinforced by societal standards, this might partially explain our findings for the males.

From a psychiatric point of view, both extremes of BMI are associated with mental disorders as eating problems (eating too much or eating too little) and changed physical activity (increased or decreased) are both considered core symptoms of major depressive disorder [25].

Crisp and McGuiness [23] conducted on middle-aged subjects (men and women) of the general population and found that obese people are at much lesser risk of developing anxiety as compared to underweight.

A long term, large prospective study that was done by Lawlor et al. (2007) [26] on middle life (4564 years old) individuals showed that high BMI levels were inversely associated with the risk of future hospital admission for anxiety symptoms.

Ross (1994) [24] concluded that there is no direct relationship between being overweight and depression in most groups.

Furthermore, Han et al. [27] found that there is no overall association between obesity and mental health disorders using the short form-36 health survey (SF-36), which is a patient-reported survey.

In addition, Terracciano et al. [28] evaluated the link between weight and personality states; the results of the personality assessment have shown that the underweight individuals have a tendency to be anxious, vulnerable, depressed, angry, and hostile.

A variety of adverse psychosocial consequences of obesity have led to the assumption that obese subjects have higher rates of anxiety as compared to normal healthy weighed individuals [29].

Simon et al. [30] mentioned that several community surveys which have been carried out in the United States and Canada have found the relationship between obesity and depressive symptoms, history of depression, and measures of psychological distress. Anxiety symptoms have shown moderate positive associations with obesity in community and clinic samples.

According to Luppino et al., (2010) [31], depression and obesity are two health issues that are increasing in prevalence worldwide, and both have a negative impact on human health status. The fact that they are both causing an increased risk of cardiovascular disease, a potential relationship between depression and obesity has been presumed and thought to be existent and has repeatedly been studied and examined.

Istvan et al. [32] mention that several studies claim the relationship of obesity with psychological disorders to be dependent on gender, as the relationship appears to be significant in woman and insignificant in men.

In a study, that was done to evaluate the association between personality aspects and body weight, authors concluded that obese individuals had more impulsiveness and low self-discipline [33].

Furthermore, Zhao et al. [34] showed that there is a high prevalence of obesity worldwide and there is 
a high risk of developing psychological disorders from obesity, whereas on the other hand, there are some studies which find no relation of anxiety to obesity or a negative correlation in men. Therefore, the accurate results regarding this issue are not yet known.

Due to the stigma of obesity, especially toward obese women the society pressures them with negative feedback and labels them with being "fat" which leads to the development of negative emotion and anxiety [35].

Impulsive individuals often switch between restricting their food intake and periods of uncontrolled eating. Moreover, changes in appetite are one of the main characteristics of depression and psychological disorders [25], [36].

Obese people usually face discrimination in their daily lives and at work. They have a lower socioeconomic status, a lower self-esteem, and enjoy a less social support. All these things can lead to mood disorders or emotional stress, which may accumulate with time leading to the development of mental disorders [37].

\section{Conclusions}

One of the most common psychological disorders that could inversely affect the human being is increased anxiety level. This condition can lead to social impairment and reduced work production among individuals. Many studies suggested that weight gain occurs from an increase in anxiety symptoms, including social isolation and sedentary lifestyle.

At the end of this scientific study, it is concluded that there is a significant negative correlation between $\mathrm{BMI}$ and anxiety level. This study concluded that BMI is inversely proportional to the anxiety status.

\section{Limitations}

The limitations of this study included small sample size, and the majority of the subjects were normal BMI; therefore, there was a shortage in subjects who were underweight or obese. Another limitation may be the current study concentrated on the relationship between BMI and anxiety status, while many other factors were not assessed in the current study outcomes. Another limitation is using the convenience sampling of Ahlia University only.

\section{Acknowledgment}

The authors would like to thank the valuable study subjects.

\section{Authors' Contributions}

All the authors have contributed equally.

\section{References}

1. Gatineau M, Dent M. Obesity and Mental Health. United Kingdom, Oxford: National Obesity Observatory; 2011.

2. Kiecolt-Glaser JK, Page GG, Marucha PT, MacCallum RC, Glaser R. Psychological influences on surgical recovery. Perspectives from psychoneuroimmunology. Am Psychol. 1998;53(11):1209-18. https://doi. org/10.1037/0003-066x.53.11.1209 PMid:9830373

3. Sobocki P, Ekman M, Agren H, Krakau I, Runeson B Mårtensson $\mathrm{B}$, et al. Health-related quality of life measured with EQ-5D in patients treated for depression in primary care. Value Health. 2007;10(2):153-60. https://doi. org/10.1111/j.1524-4733.2006.00162.x

PMid:17391424

4. Keys A, Fidanza F, Karvonen MJ, Kimura N, Taylor HL. Indices of relative weight and obesity. Int J Epidemiol. 2014;43(3):65565. https://doi.org/10.1093/ije/dyu058 PMid:24691951

5. Nuttall FQ. Body mass index: Obesity, BMI, and health: A critical review. Nutr Today. 2015;50(3):117-28.

PMid:27340299

6. Gallagher D, Visser M, Sepúlveda D, Pierson RN, Harris T, Heymsfield SB. How useful is body mass index for comparison of body fatness across age, sex, and ethnic groups? Am J Epidemiol. 1996;143(3):228-39. https://doi.org/10.1093/ oxfordjournals.aje.a008733

PMid:8561156

7. World Health Organization; 2006. Available from: https:// www.euro.who.int/HEN/Syntheses/short/20040908_1. [Last accessed 2019 May 04]

8. Zhang Y, Daquinag A, Traktuev DO, Amaya-Manzanares F, Simmons PJ, March KL, et al. White adipose tissue cells are recruited by experimental tumors and promote cancer progression in mouse models. Cancer Res. 2009;69(1):525966. https://doi.org/10.1158/0008-5472.can-08-3444 PMid:19491274

9. Gharib NM, Rasheed P. Obesity among Bahraini children and adolescents: Prevalence and associated factors. J bahrain Med Soc. 2008;20:114-23.

10. Cohen SS, Signorello LB, Cope EL, McLaughlin JK, Hargreaves MK, Zheng W, et al. Obesity and all-cause mortality among black adults and white adults. Am J Epidemiol. 2012;176(5):431-42. https://doi.org/10.1093/aje/kws032 PMid:22822174

11. Flegal KM, Kit BK, Orpana H, Graubard BI. Association of all-cause mortality with overweight and obesity using standard body mass index categories: A systematic review and meta-analysis. JAMA. 2013;309(1):71-82. https://doi.org/10.1001/jama.2012.113905 PMid:23280227

12. Bray GA. Medical consequences of obesity. J Clin Endocrino Metab. 2004;89(6):2583-9.

PMid: 15181027

13. Flegal KM, Carroll MD, Ogden CL, Curtin LR. Prevalence 
and trends in obesity among US adults, 1999-2008. JAMA. 2010;303(3):235-41. https://doi.org/10.1001/jama.2009.2014 PMid:20071471

14. Flegal KM, Kruszon-Moran D, Carroll MD, Fryar CD, Ogden CL. Trends in obesity among adults in the United States, 2005 to 2014. JAMA. 2016;315(21):2284-91. https://doi.org/10.1001/ jama.2016.6458

PMid:27272580

15. Stunkard AJ, Faith MS, Allison KC. Depression and obesity. Biol Psychiatry. 2003;54(3):330-7.

PMid: 12893108

16. Dong C, Sanchez LE, Price RA. Relationship of obesity to depression: A family-based study. Int J Obes Relat Metab Disord. 2004;28(6):790-5. https://doi.org/10.1038/sj.ijo.0802626 PMid: 15024401

17. Spitzer RL, Kroenke K, Williams JB. Validation and utility of a self-report version of PRIME-MD: The PHQ primary care study. Primary Care evaluation of mental disorders. Patient health questionnaire. JAMA. 1999;282(18):1737-44. https://doi. org/10.1001/jama.282.18.1737

PMid:10568646

18. Spitzer RL, Kroenke K, Williams JB, Löwe B. A brief measure for assessing generalized anxiety disorder: The GAD-7. Arch Intern Med. 2006;166(10):1092-7. https://doi.org/10.1001/ archinte.166.10.1092

PMid:16717171

19. Faravelli C, Guerrini Degl'Innocenti B, Giardinelli L. Epidemiology of anxiety disorders in Florence. Acta Psychiatr Scand. 1989;79(4):308-12. https://doi.org/10.1111/j.1600-0447.1989. tb10263.x PMid:2786666

20. American Psychiatric Association. Diagnostic and Statistical Manual of Mental Disorders. $4^{\text {th }}$ ed. Washington, DC: American Psychiatric Association; 2000.

21. Carter RM, Wittchen HU, Pfister H, Kessler RC. One-year prevalence of subthreshold and threshold DSM-IV generalized anxiety disorder in a nationally representative sample. Depress Anxiety. 2001;13(2):78-88. https://doi.org/10.1002/da.1020 PMid:11301924

22. McCaulay M, Mintz L, Glenn AA. Body image, self-esteem, and depression-proneness: Closing the gender gap. Sex Roles. 1998;18:381-91. https://doi.org/10.1007/bf00288390

23. Crisp AH, McGuiness B. Jolly fat: Relation between obesity and psychoneurosis in general population. $\mathrm{Br}$ Med $\mathrm{J}$. 1976;1(6000):7-9. https://doi.org/10.1136/bmj.1.6000.7 PMid: 1247732

24. Ross CE. Overweight and depression. J Health Soc Behav. 1994;35(1):63-79.

PMid:8014430

25. American Psychiatric Association. Diagnostic and Statistical Manual of Mental Disorders. $4^{\text {th }}$ ed. Washington DC: American Psychiatric Association; 1996. https://doi.org/10.1017/ s0033291700035765

26. Lawlor DA, Hart CL, Hole DJ, Gunnell D, Davey Smith G. Body mass index in middle life and future risk of hospital admission for psychoses or depression: Findings from the Renfrew/ Paisley study. Psychol Med. 2007;37(8):1151-61. https://doi. org/10.1017/s0033291707000384

\section{PMid: 17407616}

27. Han TS, Tijhuis MA, Lean ME, Seidell JC. Quality of life in relation to overweight and body fat distribution. Am J Public Health. 1998;88(12):1814-20. https://doi.org/10.2105/ajph.88.12.1814 PMid:9842379

28. Terracciano A, Sutin AR, McCrae RR, Deiana B, Ferrucci L, Schlessinger $\mathrm{D}$, et al. Facets of personality linked to underweight and overweight. Psychosom Med. 2009;71(6):682-9. https://doi. org/10.1097/psy.0b013e3181a2925b

PMid:19414622

29. Yackobovitch-Gavan M, Meshy-Tamir R, Nagelberg N Phillip M, Meyerovitch J. Psychosocial factors associated with depressive mood in Israeli obese adolescents. J Health Psychol. 2014;19(4):574-84. https://doi. org/10.1177/1359105313475901

PMid:23479303

30. Simon GE, Von Korff M, Saunders K, Miglioretti DL, Crane PK, van Belle G, et al. Association between obesity and psychiatric disorders in the US adult population. Arch Gen Psychiatry. 2006;63(7):824-30. https://doi.org/10.1001/archpsyc.63.7.824 PMid:16818872

31. Luppino FS, de Wit LM, Bouvy PF, Stijnen T, Cuijpers $P$, Penninx BW, et al. Overweight, obesity, and depression: A systematic review and meta-analysis of longitudinal studies. Arch Gen Psychiatry. 2010;67(3):220-9. https://doi.org/10.1001/ archgenpsychiatry.2010.2 PMid:20194822

32. Istvan JA, Cunningham TW, Garfinkel L. Cigarette smoking and body weight in the cancer prevention study I. Int $\mathrm{J}$ Epidemiol. 1992;21(5):849-53. https://doi.org/10.1093/ije/21.5.849 PMid:1468844

33. Sutin AR, Ferrucci L, Zonderman AB, Terracciano A. Personality and obesity across the adult life span. J Pers Soc Psychol. 2011;101(3):579-92. https://doi.org/10.1037/a0024286 PMid:21744974

34. Zhao G, Ford ES, Dhingra S, Li C, Strine TW, Mokdad AH. Depression and anxiety among US adults: Associations with body mass index. Int J Obes (Lond). 2009;33(2):257-66. https:// doi.org/10.1038/ijo.2008.268 PMid:19125163

35. Orbach S. Fat is a Feminist Issue. New York: Paddington Press; 1978.

36. Jansen A, Nederkoorn C, van Baak L, Keirse C, Guerrieri R, Havermans R. High-restrained eaters only overeat when they are also impulsive. Behav Res Ther. 2009;47(2):105-10. https:// doi.org/10.1016/j.brat.2008.10.016 PMid:19038379

37. National Institutes of Health. Clinical guidelines on the identification, evaluation, and treatment of overweight and obesity in adults--the evidence report. National institutes of health. Obes Res. 1998;6 Suppl 2:51S-209S.

PMid:9813653 